\title{
Kinetics of Reactive Diffusion in the (Sn-Cu)/Ni System at Solid-State Temperatures
}

\author{
Misako Nakayama ${ }^{1, * 1}$ and Masanori Kajihara ${ }^{2, * 2}$ \\ ${ }^{1}$ Graduate School, Tokyo Institute of Technology, Yokohama 226-8502, Japan \\ ${ }^{2}$ Department of Materials Science and Engineering, Tokyo Institute of Technology, Yokohama 226-8502, Japan
}

\begin{abstract}
The kinetics of the solid-state reactive diffusion in the ( $\mathrm{Sn}-\mathrm{Cu}) / \mathrm{Ni}$ system was experimentally observed to examine effects of addition of $\mathrm{Cu}$ into $\mathrm{Sn}$ on the growth behavior of compounds at the interconnection between the Sn-base solder and the multilayer $\mathrm{Au} / \mathrm{Ni} / \mathrm{Cu}$ conductor during energization heating. In this experiment, sandwich $(\mathrm{Sn}-\mathrm{Cu}) / \mathrm{Ni} /(\mathrm{Sn}-\mathrm{Cu})$ diffusion couples with $\mathrm{Cu}$ concentrations of $y=0.01-0.03$ were isothermally annealed at solid-state temperatures of $T=453-473 \mathrm{~K}$ for various periods up to $1972 \mathrm{~h}$, where $y$ is the mol fraction of Cu. After annealing, an intermetallic layer consisting of $(\mathrm{Cu}, \mathrm{Ni})_{6} \mathrm{Sn}_{5}$ and $\mathrm{Ni}_{3} \mathrm{Sn}_{4}$ was recognized between the $\mathrm{Sn}-\mathrm{Cu}$ and $\mathrm{Ni}$ specimens in the diffusion couple. The total thickness of the intermetallic layer is proportional to a power function of the annealing time, and the exponent of the power function takes values of $0.37-0.44$ at $T=453 \mathrm{~K}$ and those of $0.63-0.69$ at $T=473 \mathrm{~K}$. Thus, the growth of the intermetallic layer is controlled by boundary and volume diffusion at $T=453 \mathrm{~K}$. On the other hand, at $T=473 \mathrm{~K}$, interface reaction and interdiffusion contribute to the ratecontrolling process of the intermetallic growth. The addition of $\mathrm{Cu}$ into $\mathrm{Sn}$ accelerates the intermetallic growth within the experimental annealing times. [doi:10.2320/matertrans.M2015059]
\end{abstract}

(Received February 12, 2015; Accepted March 30, 2015; Published May 15, 2015)

Keywords: reactive diffusion, metallization, solder, conductor, intermetallic compounds

\section{Introduction}

Due to high electrical conductivity, Cu-base alloys are widely used as conductor materials in the electronics industry. When the Cu-base conductor is interconnected with a Sn-base solder, $\mathrm{Cu}_{6} \mathrm{Sn}_{5}$ and $\mathrm{Cu}_{3} \mathrm{Sn}$ are formed at the interconnection between the conductor and the solder during soldering and then gradually grow during energization heating at solid-state temperatures. ${ }^{1-11)}$ Since the $\mathrm{Cu}-\mathrm{Sn}$ compounds are brittle and possess high electrical resistivities, their growth deteriorates the mechanical and electrical properties of the interconnection. To inhibit the formation of the compounds, the $\mathrm{Cu}$-base conductor is usually plated with a Ni layer. However, $\mathrm{Ni}$ is not sufficiently corrosion resistant. Hence, the Ni layer is plated with a Au or Pd layer to improve corrosion resistance. ${ }^{12-15)}$

For the multilayer $\mathrm{Au} / \mathrm{Ni} / \mathrm{Cu}$ conductor with a thin $\mathrm{Au}$ layer, the Au layer quickly dissolves into a molten Sn-base solder during soldering, and then the Ni layer is contacted with the solder. As a consequence, the Ni layer is directly reacted with the solder during solid-state energization heating. The solid-state reactive diffusion in the $\mathrm{Ni} / \mathrm{Sn}$ system was experimentally examined using sandwich $\mathrm{Sn} /$ $\mathrm{Ni} / \mathrm{Sn}$ diffusion couples prepared by a diffusion bonding technique in a previous study. ${ }^{16)}$ In this experiment, the diffusion couples were isothermally annealed at temperatures of $T=433-473 \mathrm{~K}$. At the interface in the annealed diffusion couple, a layer of $\mathrm{Ni}_{3} \mathrm{Sn}_{4}$ was observed at $T=453-473 \mathrm{~K}$, but granular particles of $\mathrm{Ni}_{3} \mathrm{Sn}_{4}$ were recognized at $T=$ $433 \mathrm{~K}$. The mean thickness of the $\mathrm{Ni}_{3} \mathrm{Sn}_{4}$ layer is proportional to a power function of the annealing time. The exponent of the power function is 0.46 and 0.41 at $T=453$ and $473 \mathrm{~K}$, respectively. The exponent smaller than 0.5 indicates that the growth of $\mathrm{Ni}_{3} \mathrm{Sn}_{4}$ is controlled by boundary and volume diffusion and grain growth occurs in $\mathrm{Ni}_{3} \mathrm{Sn}_{4}$. Although the growth of $\mathrm{Ni}_{3} \mathrm{Sn}_{4}$ may be accelerated by boundary diffusion,

\footnotetext{
${ }^{* 1}$ Graduate Student, Tokyo Institute of Technology

${ }^{* 2}$ Corresponding author, E-mail: kajihara@materia.titech.ac.jp
}

the overall growth rate is smaller for $\mathrm{Ni}_{3} \mathrm{Sn}_{4}{ }^{16)}$ than for $\mathrm{Cu}_{6} \mathrm{Sn}_{5}$ and $\mathrm{Cu}_{3} \mathrm{Sn}^{3}{ }^{3,11)}$ Consequently, the Ni layer works as a barrier against the reactive diffusion at the interconnection between the $\mathrm{Sn}$-base solder and the multilayer $\mathrm{Au} / \mathrm{Ni} / \mathrm{Cu}$ conductor with a thin Au layer during solid-state energization heating.

Since the price is much lower for $\mathrm{Cu}$ than for $\mathrm{Ag}, \mathrm{Sn}-\mathrm{Cu}$ alloys are more preferentially used as a low-cost $\mathrm{Pb}$-free solder than $\mathrm{Sn}-\mathrm{Ag}$ alloys. In the $\mathrm{Sn}-\mathrm{Cu}$ solder, small particles of $\mathrm{Cu}_{6} \mathrm{Sn}_{5}$ are dispersed in the $\mathrm{Sn}$ matrix. The dispersion of $\mathrm{Cu}_{6} \mathrm{Sn}_{5}$ in the solder may influence the kinetics of the reactive diffusion between the Sn matrix and the Ni layer at the interconnection. Unfortunately, however, reliable information on such influence is rather limited. To examine this influence, the kinetics of the reactive diffusion in the $(\mathrm{Sn}-\mathrm{Cu}) / \mathrm{Ni}$ system was experimentally observed at solid-state temperatures of $T=453-473 \mathrm{~K}$ using sandwich $(\mathrm{Sn}-\mathrm{Cu}) / \mathrm{Ni} /(\mathrm{Sn}-$ $\mathrm{Cu}$ ) diffusion couples with $\mathrm{Cu}$ mol fractions of $0.01-0.03$ in the present study.

\section{Experimental}

Binary $\mathrm{Sn}-\mathrm{Cu}$ alloys with $\mathrm{Cu}$ concentrations of $y=0.01$, 0.02 and 0.03 were made as $25 \mathrm{~g}$ button ingots by argon arc melting from pure $\mathrm{Sn}$ and $\mathrm{Cu}$ with purities of 99.99 and $99.96 \%$, respectively, where $y$ is the mol fraction of $\mathrm{Cu}$. Plate specimens with a size of $12 \mathrm{~mm} \times 5 \mathrm{~mm} \times 2 \mathrm{~mm}$ were prepared by cold rolling and spark erosion from the button ingots. The plate specimens were isothermally heated in an oil bath with silicone oil at $473 \mathrm{~K}$ for $2 \mathrm{~h}$, followed by water quenching. The two surfaces with an area of $12 \mathrm{~mm} \times 5 \mathrm{~mm}$ of each heated $\mathrm{Sn}-\mathrm{Cu}$ plate specimen were mechanically polished on \# 800 emery paper. One of the two polished surfaces was again mechanically polished on \# 1500-4000 emery papers until a depth of $100 \mu \mathrm{m}$ and then finished using diamond with a diameter of $1 \mu \mathrm{m}$.

Sheet specimens with a size of $20 \mathrm{~mm} \times 7 \mathrm{~mm} \times 0.2 \mathrm{~mm}$ were cut from a pure $\mathrm{Ni}$ commercial sheet with dimensions of $300 \mathrm{~mm} \times 100 \mathrm{~mm} \times 0.2 \mathrm{~mm}$ and purity of $99.97 \%$ and then 
separately annealed in evacuated silica capsules at $1173 \mathrm{~K}$ for $2 \mathrm{~h}$, followed by air cooling without breaking the capsules. The annealed sheet specimens were chemically polished in nitrohydrochloric acid for $60 \mathrm{~s}$.

After chemical polishing, a $\mathrm{Ni}$ sheet specimen was immediately sandwiched between the finished surfaces of two freshly prepared $\mathrm{Sn}-\mathrm{Cu}$ plate specimens in ethanol by the technique used in a previous study. ${ }^{11)}$ The sandwich (Sn$\mathrm{Cu} / \mathrm{Ni} /(\mathrm{Sn}-\mathrm{Cu})$ couples were completely dried and then heat treated for diffusion bonding in the oil bath for 69 and $44.5 \mathrm{~h}$ at 453 and $473 \mathrm{~K}$, respectively. After the heat treatment, the diffusion couples were isothermally annealed at $453-473 \mathrm{~K}$ for various times up to $1903 \mathrm{~h}$. The summation of the heat-treating and annealing times is hereafter merely called the annealing time $t$, and the annealing temperature is denoted by $T$. The chemical composition of the $\mathrm{Sn}-\mathrm{Cu}$ alloy is described as $\mathrm{Sn}-y \mathrm{Cu}$. The $\mathrm{Sn}-0.01 \mathrm{Cu}, \mathrm{Sn}-0.02 \mathrm{Cu}$ and $\mathrm{Sn}-0.03 \mathrm{Cu}$ alloys are designated alloys $\mathrm{C} 1, \mathrm{C} 2$ and $\mathrm{C} 3$, respectively, and the diffusion couples with alloys $\mathrm{C} 1, \mathrm{C} 2$ and $\mathrm{C} 3$ are called diffusion couples $\mathrm{C} 1, \mathrm{C} 2$ and $\mathrm{C} 3$, respectively. Cross-sections of the annealed diffusion couple were mechanically polished using diamond with diameters of 15,3 and $1 \mu \mathrm{m}$, and then finished with an OP-S liquid manufactured by Struers Ltd. The microstructure of the crosssection was observed by differential interference contrast optical microscopy (DICOM). Concentrations of $\mathrm{Sn}, \mathrm{Cu}$ and $\mathrm{Ni}$ in each phase on the cross-section were measured by electron probe microanalysis (EPMA) using pure $\mathrm{Sn}, \mathrm{Cu}$ and $\mathrm{Ni}$ with purity of $99.99 \%$ as standard specimens under the following conditions: the accelerating voltage was $20 \mathrm{kV}$; the probe current was $5 \mathrm{nA}$; the analyzing crystal was polyethylene terephthalate (PET) for $\mathrm{Sn}-\mathrm{L}_{\alpha}$ and lithium fluoride (LiF) for $\mathrm{Cu}-\mathrm{K}_{\alpha}$ and $\mathrm{Ni}-\mathrm{K}_{\alpha}$; and the chemical composition was evaluated by a standard ZAF correction technique.

\section{Results and Discussion}

\subsection{Microstructure}

A typical DICOM image for the cross-section of diffusion couple C1 with $T=473 \mathrm{~K}$ and $t=787.5 \mathrm{~h}\left(2.84 \times 10^{6} \mathrm{~s}\right)$ is shown in Fig. 1. In this figure, the top and bottom regions are the $\mathrm{Sn}-\mathrm{Cu}$ and $\mathrm{Ni}$ specimens, respectively. As can be seen, a layer with rather uniform thickness is formed at the original interface between the $\mathrm{Sn}-\mathrm{Cu}$ and $\mathrm{Ni}$ specimens. To identify each phase, concentration profiles of $\mathrm{Sn}, \mathrm{Cu}$ and $\mathrm{Ni}$ were determined by EPMA along the direction normal to the original interface. A result for diffusion couple $\mathrm{C} 2$ with $T=473 \mathrm{~K}$ and $t=1264.5 \mathrm{~h}\left(4.55 \times 10^{6} \mathrm{~s}\right)$ is indicated in Fig. 2. In Fig. 2, the ordinate and the abscissa show the mol fraction $y_{i}$ of component $i$ and the distance $x$ measured from an arbitrary origin, respectively, and open circles, squares and rhombuses represent the mol fractions $y_{\mathrm{Sn}}, y_{\mathrm{Cu}}$ and $y_{\mathrm{Ni}}$, respectively. As can be seen, the layer consists of two compounds. They are $\mathrm{Ni}_{3} \mathrm{Sn}_{4}$ and $(\mathrm{Cu}, \mathrm{Ni})_{6} \mathrm{Sn}_{5}$ on the $\mathrm{Ni}$ and $\mathrm{Sn}-\mathrm{Cu}$ sides, respectively. The thickness is much smaller for $\mathrm{Ni}_{3} \mathrm{Sn}_{4}$ than for $(\mathrm{Cu}, \mathrm{Ni})_{6} \mathrm{Sn}_{5}$. Furthermore, the concentration of $\mathrm{Cu}$ in $\mathrm{Ni}_{3} \mathrm{Sn}_{4}$ is smaller than that of $\mathrm{Ni}$ in $(\mathrm{Cu}, \mathrm{Ni})_{6} \mathrm{Sn}_{5}$. Hereafter, the $(\mathrm{Cu}, \mathrm{Ni})_{6} \mathrm{Sn}_{5}+\mathrm{Ni}_{3} \mathrm{Sn}_{4}$ two-phase layer is merely called the intermetallic layer. If we observe the edge of diffusion couple on the cross-section, we can find the

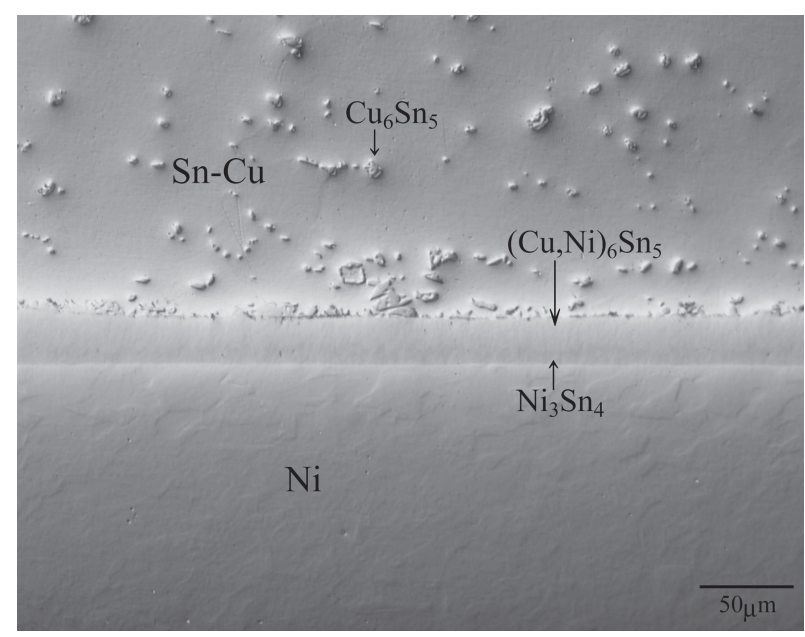

Fig. 1 Cross-sectional DICOM image of diffusion couple $\mathrm{C} 1$ annealed at $T=473 \mathrm{~K}$ for $t=787.5 \mathrm{~h}\left(2.84 \times 10^{6} \mathrm{~s}\right)$

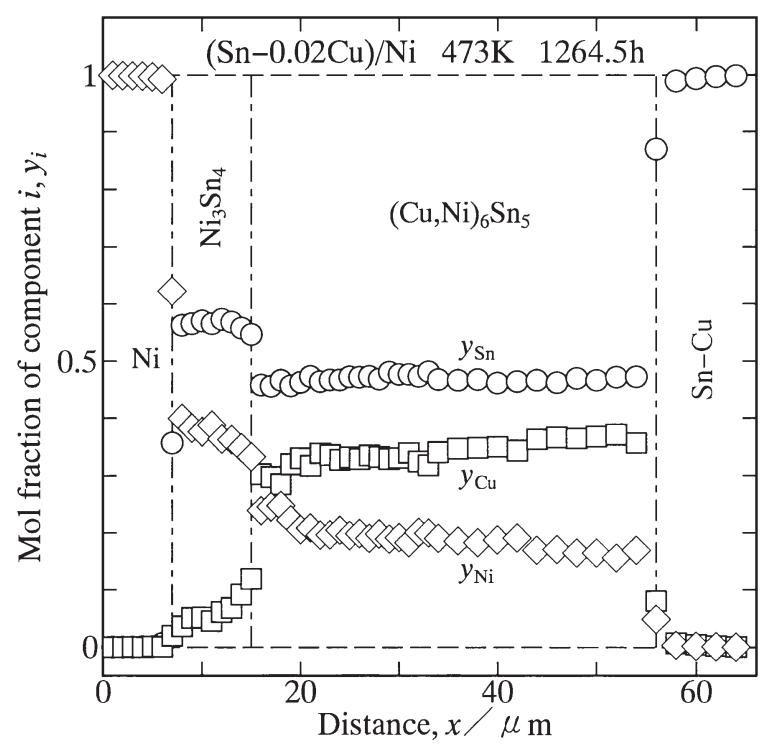

Fig. 2 Concentration profiles of $\mathrm{Sn}, \mathrm{Cu}$ and $\mathrm{Ni}$ across the intermetallic layer for diffusion couple $\mathrm{C} 2$ annealed at $T=473 \mathrm{~K}$ for $t=1264.5 \mathrm{~h}$ $\left(4.55 \times 10^{6} \mathrm{~s}\right)$.

location of the original $(\mathrm{Sn}-\mathrm{Cu}) / \mathrm{Ni}$ interface. This observation indicates that the intermetallic layer grows mainly into the $\mathrm{Sn}-\mathrm{Cu}$ specimen but slightly towards the Ni specimen. The EPMA measurement was conducted also for diffusion couples $\mathrm{C} 1$ and $\mathrm{C} 3$. Since the volume fraction of $\mathrm{Ni}_{3} \mathrm{Sn}_{4}$ in the intermetallic layer gradually decreases with increasing $\mathrm{Cu}$ concentration of the $\mathrm{Sn}-\mathrm{Cu}$ specimen, however, $\mathrm{Ni}_{3} \mathrm{Sn}_{4}$ is rather invisible at shorter annealing times for diffusion couple C3.

Recently, the phase equilibria at the Sn-rich corner in the ternary $\mathrm{Sn}-\mathrm{Cu}-\mathrm{Ni}$ system were experimentally determined at solid-state temperatures in a previous study. ${ }^{17)}$ The isothermal section at $T=473 \mathrm{~K}$ of the phase diagram in this ternary system is shown in Fig. 3. As can be seen, a three-phase equilibrium of $\mathrm{Sn}+(\mathrm{Cu}, \mathrm{Ni})_{6} \mathrm{Sn}_{5}+\mathrm{Ni}_{3} \mathrm{Sn}_{4}$ appears at this temperature. According to the tie-triangle of this three-phase equilibrium, the solubility ${ }^{\mathrm{s}} y_{\mathrm{Ni}}^{\mathrm{Cu}_{6} \mathrm{Sn}_{5}}$ of $\mathrm{Ni}$ in $\mathrm{Cu}_{6} \mathrm{Sn}_{5}$ is 0.224 , and that ${ }^{\mathrm{s}} y_{\mathrm{Cu}}^{\mathrm{Ni}_{3} \mathrm{Sn}_{4}}$ of $\mathrm{Cu}$ in $\mathrm{Ni}_{3} \mathrm{Sn}_{4}$ is 0.046 . ${ }^{17)}$ Hence, ${ }^{\mathrm{s}} y_{\mathrm{Cu}}^{\mathrm{Ni}_{3} \mathrm{Sn}_{4}}$ is 


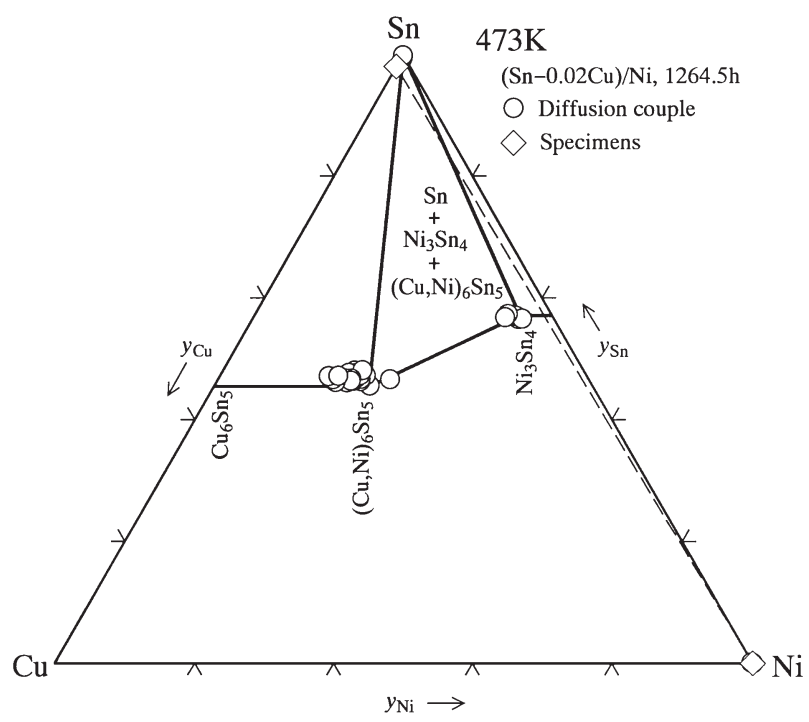

Fig. 3 Diffusion path for the concentration profiles shown in Fig. 2. The three-phase equilibrium of $\mathrm{Sn}+(\mathrm{Cu}, \mathrm{Ni})_{6} \mathrm{Sn}_{5}+\mathrm{Ni}_{3} \mathrm{Sn}_{4}$ in the ternary $\mathrm{Sn}-$ $\mathrm{Cu}-\mathrm{Ni}$ system $^{17)}$ is also indicated as a tie-triangle.

much smaller than ${ }^{\mathrm{s}} y_{\mathrm{Ni}}^{\mathrm{Cu}_{6} \mathrm{Sn}_{5}}$. Therefore, in Fig. $3, \mathrm{Cu}_{6} \mathrm{Sn}_{5}$ is described as $(\mathrm{Cu}, \mathrm{Ni})_{6} \mathrm{Sn}_{5}$, but $\mathrm{Ni}_{3} \mathrm{Sn}_{4}$ is merely expressed as $\mathrm{Ni}_{3} \mathrm{Sn}_{4}$. The concentration profiles across the intermetallic layer for diffusion couple C2 in Fig. 2 are plotted as open circles in Fig. 3. On the other hand, in Fig. 3, open rhombuses represent the chemical compositions of the $\mathrm{Sn}-$ $\mathrm{Cu}$ and $\mathrm{Ni}$ specimens for diffusion couple $\mathrm{C} 2$. As can be seen, the open circles for $(\mathrm{Cu}, \mathrm{Ni})_{6} \mathrm{Sn}_{5}$ and $\mathrm{Ni}_{3} \mathrm{Sn}_{4}$ are located in the neighborhood of the $(\mathrm{Cu}, \mathrm{Ni})_{6} \mathrm{Sn}_{5}$ and $\mathrm{Ni}_{3} \mathrm{Sn}_{4}$ corners, respectively, of the $\mathrm{Sn}+\left(\mathrm{Cu}, \mathrm{Ni}_{6} \mathrm{Sn}_{5}+\mathrm{Ni}_{3} \mathrm{Sn}_{4}\right.$ tie-triangle. Thus, the mol fraction $y_{\mathrm{Ni}}^{\mathrm{Cu}_{6} \mathrm{Sn}_{5}}$ of $\mathrm{Ni}$ in $(\mathrm{Cu}, \mathrm{Ni})_{6} \mathrm{Sn}_{5}$ and that $y_{\mathrm{Cu}}^{\mathrm{Ni}_{3} \mathrm{Sn}_{4}}$ of $\mathrm{Cu}$ in $\mathrm{Ni}_{3} \mathrm{Sn}_{4}$ in Fig. 2 are close to the solubilities ${ }^{\mathrm{s}} y_{\mathrm{Ni}} \mathrm{Cu}_{6} \mathrm{Sn}_{5}$ and ${ }^{\mathrm{s}} y_{\mathrm{Cu}} \mathrm{Ni}_{3} \mathrm{Sn}_{4}$, respectively.

As indicated in Fig. 1, small particles of $\mathrm{Cu}_{6} \mathrm{Sn}_{5}$ are thinly dispersed in the $\mathrm{Sn}$ matrix of the $\mathrm{Sn}-\mathrm{Cu}$ specimen. Furthermore, the solubilities of $\mathrm{Cu}$ and $\mathrm{Ni}$ in the Sn matrix are negligible as shown in Fig. 3. Therefore, in the early stages of the reactive diffusion, a very thin $\mathrm{Ni}_{3} \mathrm{Sn}_{4}$ layer is formed at the interface between the $\mathrm{Sn}$ matrix and the $\mathrm{Ni}$ specimen. As the annealing time increases, $\mathrm{Cu}$ atoms are transported from the $\mathrm{Cu}_{6} \mathrm{Sn}_{5}$ particles to the $\mathrm{Ni}_{3} \mathrm{Sn}_{4}$ layer through the $\mathrm{Sn}$ matrix. The mol fraction $y_{\mathrm{Cu}}^{\mathrm{Ni}_{3} \mathrm{Sn}_{4}}$ of $\mathrm{Cu}$ in $\mathrm{Ni}_{3} \mathrm{Sn}_{4}$ is increased by the $\mathrm{Cu}$-atoms transportation and then

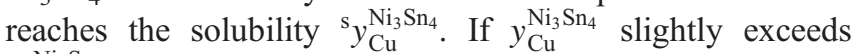

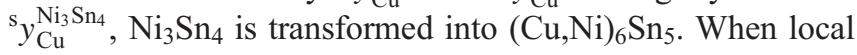
equilibrium is realized at the interface between $\left(\mathrm{Cu}, \mathrm{Ni}_{6} \mathrm{Sn}_{5}\right.$ and $\mathrm{Ni}_{3} \mathrm{Sn}_{4}, y_{\mathrm{Ni}}^{\mathrm{Cu}_{6} \mathrm{Sn}_{5}}$ and $y_{\mathrm{Cu}}^{\mathrm{Ni}_{3} \mathrm{Sn}_{4}}$ coincide with ${ }^{\mathrm{s}} y_{\mathrm{Ni}}^{\mathrm{Cu}_{6} \mathrm{Sn}_{5}}$ and ${ }^{\mathrm{s}} y_{\mathrm{Cu}}^{\mathrm{Ni}_{3} \mathrm{Sn}_{4}}$, respectively, at the interface. Since the $(\mathrm{Cu}, \mathrm{Ni})_{6} \mathrm{Sn}_{5} /$ $\mathrm{Ni}_{3} \mathrm{Sn}_{4}$ interface is produced by the transformation, it is not so clearly distinguishable in cross-sectional DICOM images as shown in Fig. 1.

\subsection{Growth behavior of intermetallic layer}

From the cross-sectional DICOM images like Fig. 1, the area $A_{j}$ of the intermetallic layer corresponding to the partial length $w_{j}$ of the original $(\mathrm{Sn}-\mathrm{Cu}) / \mathrm{Ni}$ interface were measured for cross-section $j$. The sums $A$ and $w$ were obtained by the equations $^{11)}$
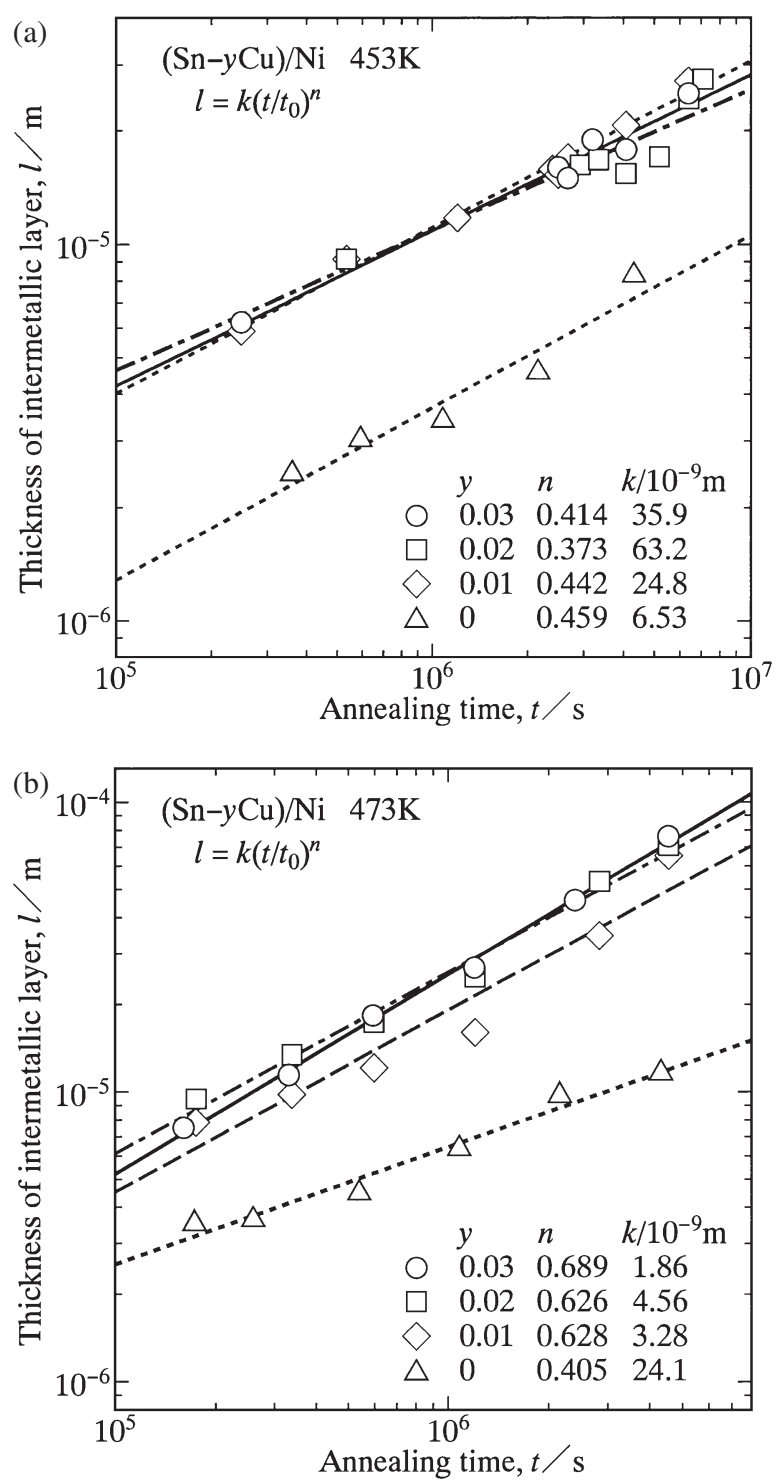

Fig. 4 The total thickness $l$ of the intermetallic layer versus the annealing time $t$ shown as open rhombuses, squares and circles for $y=0.01,0.02$ and 0.03 , respectively: (a) $T=453 \mathrm{~K}$ and (b) $T=473 \mathrm{~K}$. The corresponding results of $y=0^{16)}$ are also indicated as open triangles.

$$
A=\sum_{j=1}^{m} A_{j}
$$

and

$$
w=\sum_{j=1}^{m} w_{j}
$$

from $A_{j}$ and $w_{j}$, respectively, where $w_{j}=422 \mu \mathrm{m}$ and $m \geq 5$. Using the values of $A$ and $w$, the total thickness $l$ of the intermetallic layer was evaluated at each annealing time $t$ as follows: ${ }^{11)}$

$$
l=\frac{A}{w} .
$$

The results of diffusion couples $\mathrm{C} 1, \mathrm{C} 2$ and $\mathrm{C} 3$ are plotted as open rhombuses, squares and circles, respectively, in Fig. 4, where the ordinate and the abscissa show the logarithms of $l$ and $t$, respectively. In this figure, open triangles indicate the corresponding results of diffusion couple $\mathrm{C} 0$ reported in a 


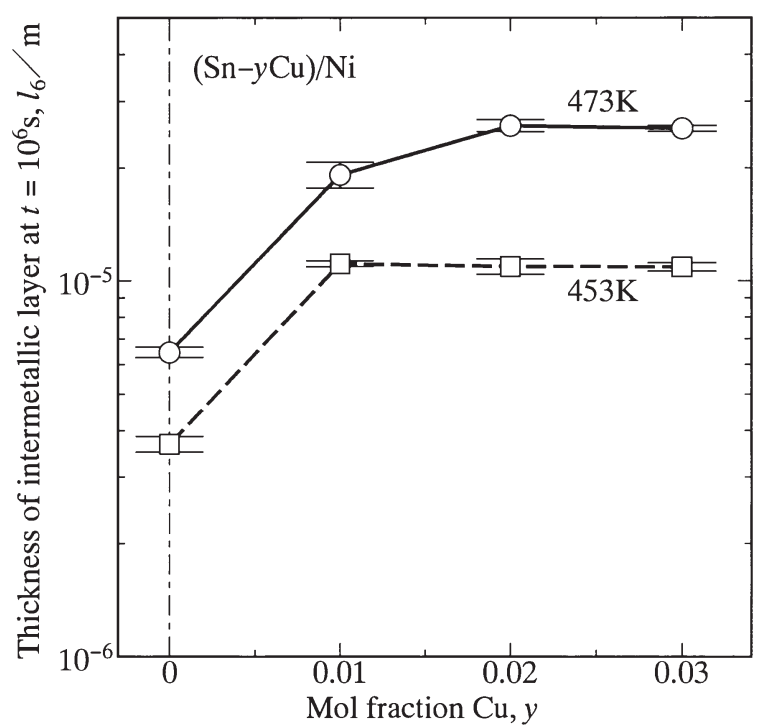

Fig. 5 The thickness $l_{6}$ at $t=10^{6} \mathrm{~s}$ versus the mol fraction $y$ of $\mathrm{Cu}$ in the $\mathrm{Sn}-\mathrm{Cu}$ alloy shown as open squares and circles for $T=453$ and $473 \mathrm{~K}$, respectively, with error bars. The corresponding results of $y=0^{16)}$ are also represented.

previous study. ${ }^{16)}$ Here, diffusion couple C0 stands for the $\mathrm{Sn} / \mathrm{Ni} / \mathrm{Sn}$ diffusion couple with $y=0 .{ }^{16)}$ Figure 4(a) and 4(b) indicates the results for $T=453$ and $473 \mathrm{~K}$, respectively. As can be seen, the thickness $l$ monotonically increases with increasing annealing time $t$. Furthermore, the plotted points for each diffusion couple lie well on a straight line. Consequently, $l$ is expressed as a power function of $t$ as follows.

$$
l=k\left(\frac{t}{t_{0}}\right)^{n}
$$

Here, $t_{0}$ is unit time, $1 \mathrm{~s}$. It is adopted to make the argument $t / t_{0}$ of the power function dimensionless. The proportionality coefficient $k$ has the same dimension as the thickness $l$, and the exponent $n$ is dimensionless. From the open symbols plotted in Fig. 4, $k$ and $n$ in eq. (3) were determined by the least-squares method as shown with various straight lines. The determined values are shown in Fig. 4. Since $n$ varies depending on $y$, it is rather difficult to find a systematic relationship between $k$ and $y$. Therefore, to estimate the composition dependence of the overall growth rate of the intermetallic layer, the thickness $l_{6}$ at $t=10^{6} \mathrm{~s}$ is plotted against $y$ as open squares and circles for $T=453$ and $473 \mathrm{~K}$, respectively, with error bars in Fig. 5. Hereafter, the error bar represents the standard error. For $T=453-473 \mathrm{~K}, l_{6}$ monotonically increases with increasing value of $y$ at $y<0.1$ but becomes rather insensitive to $y$ at $y>0.1$. As previously mentioned, the intermetallic layer consists of $\mathrm{Ni}_{3} \mathrm{Sn}_{4}$ and $(\mathrm{Cu}, \mathrm{Ni})_{6} \mathrm{Sn}_{5}$. As the value of $y$ increases, the volume fraction of $(\mathrm{Cu}, \mathrm{Ni})_{6} \mathrm{Sn}_{5}$ increases, but that of $\mathrm{Ni}_{3} \mathrm{Sn}_{4}$ decreases. According to the observations in previous studies, ${ }^{11,16,17)}$ the layer growth is much faster for $(\mathrm{Cu}, \mathrm{Ni})_{6} \mathrm{Sn}_{5}$ than for $\mathrm{Ni}_{3} \mathrm{Sn}_{4}$. Consequently, the overall growth rate of the intermetallic layer monotonically increases with increasing value of $y$. At larger values of $y$, however, the volume fraction $f$ is much greater for $(\mathrm{Cu}, \mathrm{Ni})_{6} \mathrm{Sn}_{5}$ than for $\mathrm{Ni}_{3} \mathrm{Sn}_{4}$, and hence the dependence of $f$ on $y$ becomes less
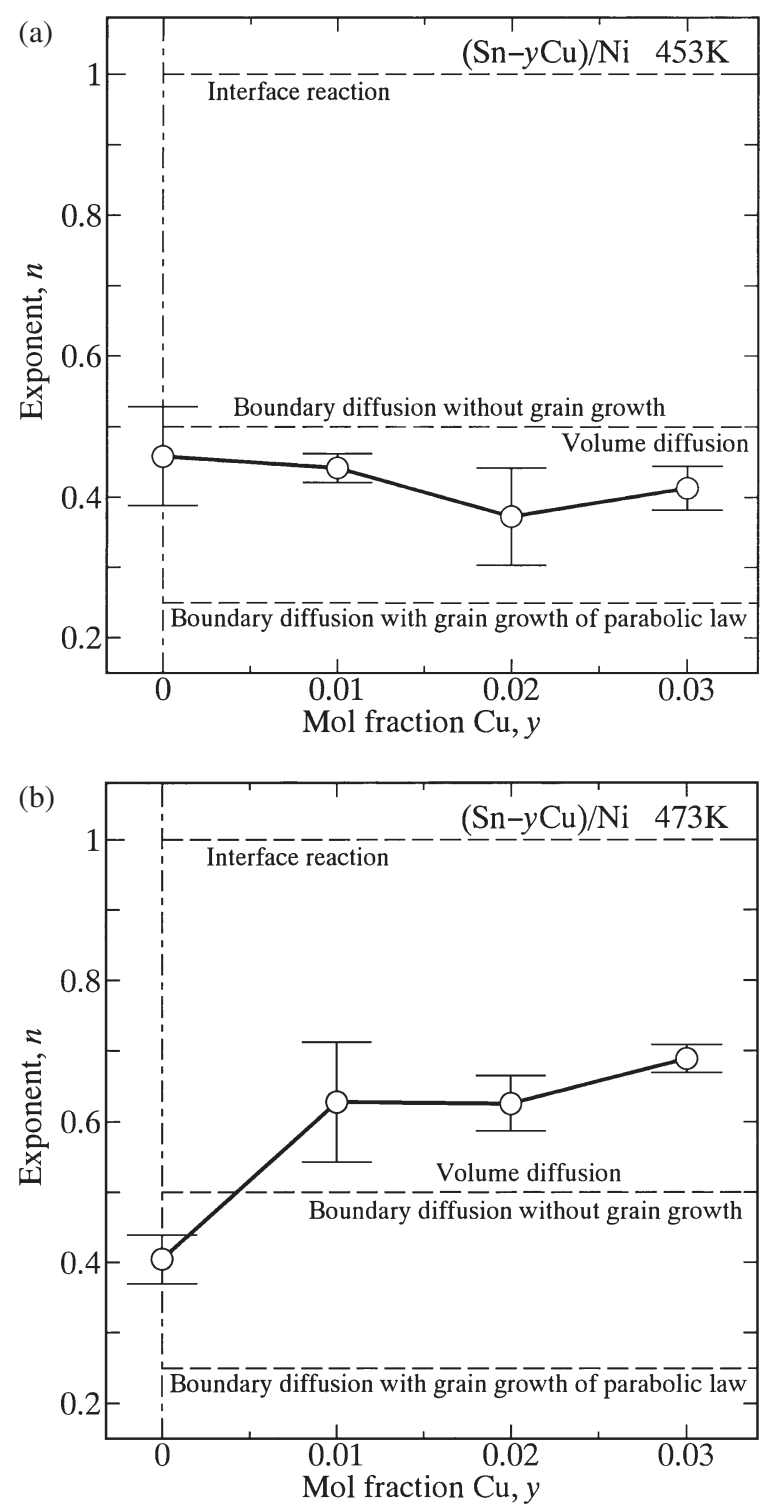

Fig. 6 The exponent $n$ versus the mol fraction $y$ of $\mathrm{Cu}$ in the $\mathrm{Sn}-\mathrm{Cu}$ alloy shown as open circles with error bars: (a) $T=453 \mathrm{~K}$ and (b) $T=473 \mathrm{~K}$. The corresponding results of $y=0^{16)}$ are also represented.

remarkable. This is the reason why $l_{6}$ monotonically increases with increasing value of $y$ at $y<0.1$ but becomes rather insensitive to $y$ at $y>0.1$.

\subsection{Rate-controlling process of intermetallic growth}

The values of $n$ at $T=453$ and $473 \mathrm{~K}$ are plotted against $y$ as open circles with error bars in Fig. 6(a) and 6(b), respectively. If the layer growth of the intermetallic layer is controlled by volume diffusion, $n$ is equal to $0.5 .{ }^{18-27)}$ On the other hand, boundary diffusion may govern the layer growth at low temperatures where volume diffusion is frozen out. When the layer growth is controlled by boundary diffusion across the intermetallic layer and grain growth occurs in the intermetallic layer, $n$ becomes smaller than $0.5 .^{28)}$ For $y=$ $0-0.03$ at $T=453 \mathrm{~K}, n$ takes values of $0.37-0.46$, and thus boundary diffusion mainly governs the layer growth. Such a rate-controlling process works also for $y=0$ at $T=473 \mathrm{~K}$. On the other hand, $n$ takes values of $0.63-0.69$ for $y=0.01-$ 0.03 at $T=473 \mathrm{~K}$. If the interface reaction at the moving 
interface controls the layer growth, $n$ is equivalent to unity. $^{29-37)}$ As mentioned in Section 3.1, the intermetallic layer grows predominantly into the $\mathrm{Sn}-\mathrm{Cu}$ specimen. Furthermore, $(\mathrm{Cu}, \mathrm{Ni})_{6} \mathrm{Sn}_{5}$ and $\mathrm{Ni}_{3} \mathrm{Sn}_{4}$ are located on the $\mathrm{Sn}-\mathrm{Cu}$ and Ni sides, respectively. Thus, the values $n=0.63-$ 0.69 indicate that the layer growth is governed by the interface reaction at the migrating $(\mathrm{Sn}-\mathrm{Cu}) /\left(\mathrm{Cu}, \mathrm{Ni}_{6}\right)_{6} \mathrm{Sn}_{5}$ interface as well as the interdiffusion across the intermetallic layer. Such a mixed rate-controlling process of reactive diffusion has been observed for various metal systems. For instance, the reactive diffusion in the $(\mathrm{Cu}-\mathrm{Sn}) / \mathrm{Nb}$ system was experimentally examined using diffusion couples consisting of $\mathrm{Cu}-\mathrm{Sn}$ alloys and $\mathrm{Nb}$ in previous studies. ${ }^{29-31)}$ In these experiments, the diffusion couple was isothermally annealed at $T=923-1053 \mathrm{~K}$. During annealing, a singlephase $\mathrm{Nb}_{3} \mathrm{Sn}$ layer is formed at the original $(\mathrm{Cu}-\mathrm{Sn}) / \mathrm{Nb}$ interface in the diffusion couple and grows mainly towards the $\mathrm{Nb}$. Here, $\mathrm{Nb}_{3} \mathrm{Sn}$ is one of the most important superconducting materials. According to the results in Fig. 5, the overall growth rate of the intermetallic layer and thus the migration rate of the $(\mathrm{Sn}-\mathrm{Cu}) /(\mathrm{Cu}, \mathrm{Ni})_{6} \mathrm{Sn}_{5}$ interface is greater for $y=0.01-0.03$ than for $y=0$. For the fast interface migration, the interface reaction is a bottleneck for the overall layer growth, and hence $n$ becomes greater than $0.5 .^{36,37)}$ Therefore, at $T=473 \mathrm{~K}, n$ is greater than 0.5 for $y=0.01-0.03$, though $n$ is smaller than 0.5 for $y=0$. As the annealing temperature $T$ decreases, the interdiffusion across the intermetallic layer becomes sluggish, and thus the interface reaction is no longer a bottleneck. Consequently, at $T=453 \mathrm{~K}, n$ is smaller than 0.5 not only for $y=0$ but also for $y=0.01-0.03$.

\section{Conclusions}

The solid-state reactive diffusion in the $(\mathrm{Sn}-\mathrm{Cu}) / \mathrm{Ni}$ system was experimentally observed using the $(\mathrm{Sn}-\mathrm{Cu}) /$ $\mathrm{Ni} /(\mathrm{Sn}-\mathrm{Cu})$ diffusion couples with $\mathrm{Cu}$ mol fractions of $y=$ $0.01-0.03$. The diffusion couples were isothermally annealed in the temperature range of $T=453-473 \mathrm{~K}$ for various times up to $t=1972 \mathrm{~h}$. During annealing, the $(\mathrm{Cu}, \mathrm{Ni})_{6} \mathrm{Sn}_{5}+$ $\mathrm{Ni}_{3} \mathrm{Sn}_{4}$ two-phase layer is formed at the original $(\mathrm{Sn}-\mathrm{Cu}) /$ $\mathrm{Ni}$ interface in the diffusion couple. The total thickness of the two-phase layer is proportional to a power function of the annealing time. The exponent of the power function takes vales of $0.37-0.44$ at $T=453 \mathrm{~K}$ and those of $0.63-0.69$ at $T=473 \mathrm{~K}$. Therefore, at $T=453 \mathrm{~K}$, the growth of the twophase layer is controlled by boundary and volume diffusion. In contrast, at $T=473 \mathrm{~K}$, interface reaction as well as interdiffusion contributes to the rate-controlling process of the layer growth. The overall growth of the two-phase layer is accelerated by the addition of $\mathrm{Cu}$ into $\mathrm{Sn}$.

\section{Acknowledgements}

The present study was supported by the Iketani Science and Technology Foundation in Japan. The study was also partially supported by a Grant-in-Aid for Scientific Research from the Ministry of Education, Culture, Sports, Science and Technology of Japan.

\section{REFERENCES}

1) L. Zakraysek: Welding Res. Suppl. Nov. (1972) 536-541.

2) K. N. Tu: Acta Metall. 21 (1973) 347-354.

3) M. Onishi and H. Fujibuchi: Trans. JIM 16 (1975) 539-547.

4) H. N. Keller: IEEE Trans. Compon. Hybrids Manuf. Tech. 2 (1979) 180-195.

5) H. N. Keller and J. M. Morabito: Surf. Interface Anal. 3 (1981) 16-22.

6) J. O. G. Parent, D. D. L. Chung and I. M. Bernstein: J. Mater. Sci. 23 (1988) 2564-2572.

7) A. J. Sunwoo, J. W. Morris, Jr. and G. K. Lucey, Jr.: Metall. Trans. A 23 (1992) 1323-1332.

8) P. T. Vianco, P. F. Hlava and A. L. Kilgo: J. Electr. Mater. 23 (1994) 583-594.

9) D. R. Frear and P. T. Vianco: Metall. Trans. A 25 (1994) 1509-1523.

10) S. Choi, T. R. Bieler, J. P. Lucas and K. N. Subramanian: J. Electr. Mater. 28 (1999) 1209-1215.

11) T. Takenaka, S. Kano, M. Kajihara, N. Kurokawa and K. Sakamoto: Mater. Sci. Eng. A 396 (2005) 115-123.

12) C. Wright: IEEE Trans. Parts Hybrids Packag. 13 (1977) 202-207.

13) H. N. Keller: IEEE Trans. Compon. Hybrids Manuf. Tech. 5 (1982) $408-419$.

14) E. I.-B. Hannech and C. R. Hall: Mater. Sci. Tech. 8 (1992) 817-824.

15) G. Ghosh: Acta Mater. 48 (2000) 3719-3738.

16) M. Mita, M. Kajihara, N. Kurokawa and K. Sakamoto: Mater. Sci. Eng. A 403 (2005) 269-275.

17) W. Shinmei: Master Thesis, Tokyo Institute of Technology, (2013).

18) M. Kajihara: Acta Mater. 52 (2004) 1193-1200.

19) M. Kajihara: Mater. Sci. Eng. A 403 (2005) 234-240.

20) M. Kajihara: Defect Diffusion Forum 249 (2006) 91-96.

21) M. Kajihara: Mater. Trans. 46 (2005) 2142-2149.

22) M. Kajihara: Mater. Trans. 47 (2006) 1480-1484.

23) M. Kajihara and T. Yamashina: J. Mater. Sci. 42 (2007) 2432-2442.

24) M. Kajihara: Mater. Trans. 49 (2008) 715-722.

25) M. Kajihara: J. Mater. Sci. 44 (2009) 2109-2118.

26) M. Kajihara: Mater. Trans. 51 (2010) 1242-1248.

27) M. Kajihara: Mater. Trans. 53 (2012) 1896-1904.

28) A. Furuto and M. Kajihara: Mater. Trans. 49 (2008) 294-303.

29) Y. Muranishi and M. Kajihara: Mater. Sci. Eng. A 404 (2005) 33-41.

30) T. Hayase and M. Kajihara: Mater. Sci. Eng. A 433 (2006) 83-89.

31) K. Mikami and M. Kajihara: J. Mater. Sci. 42 (2007) 8178-8188.

32) M. Kajihara and Y. Tejima: J. Phys. Conf. Ser. 165 (2009) 012091.

33) Y. Tejima, S. Nakamura and M. Kajihara: J. Mater. Sci. 45 (2010) 919928.

34) M. O, Y. Takamatsu and M. Kajihara: Mater. Trans. 55 (2014) 10581064 .

35) M. Hashiba, K. Masui and M. Kajihara: Mater. Trans. 56 (2015) 30-39.

36) Y. Yamamoto and M. Kajihara: Mater. Trans. 42 (2001) 1763-1770.

37) Y. Yamamoto and M. Kajihara: J. Electr. Mater. 37 (2008) 1710-1720. 